\title{
Numerical simulations of flow and sediment transport within the Ning-Meng reach of the Yellow River, northern China
}

\author{
DOU Shentang ${ }^{1}$, YU Xin ${ }^{1}$, DU Heqiang ${ }^{2 *}$, ZHANG Fangxiu ${ }^{1}$ \\ ${ }^{1}$ Yellow River Institute of Hydraulic Research, Yellow River Conservancy Commission, Zhengzhou 450003, China; \\ ${ }^{2}$ Northwest Institute of Eco-Environment and Resources, Chinese Academy of Sciences, Lanzhou 730000, China
}

\begin{abstract}
Effective management of a river reach requires a sound understanding of flow and sediment transport generated by varying natural and artificial runoff conditions. Flow and sediment transport within the Ning-Meng reach of the Yellow River (NMRYR), northern China are controlled by a complex set of factors/processes, mainly including four sets of factors: (1) aeolian sediments from deserts bordering the main stream; (2) inflow of water and sediment from numerous tributaries; (3) impoundment of water by reservoir/hydro-junction; and (4) complex diversion and return of irrigation water. In this study, the 1-D flow \& sediment transport model developed by the Yellow River Institute of Hydraulic Research was used to simulate the flow and sediment transport within the NMRYR from 2001 to 2012. All four sets of factors that primarily control the flow and sediment transport mentioned above were considered in this model. Compared to the measured data collected from the hydrological stations along the NMRYR, the simulated flow and sediment transport values were generally acceptable, with relative mean deviation between measured and simulated values of $<15 \%$. However, simulated sediment concentration and siltation values within two sub-reaches (i.e., Qingtongxia Reservoir to Bayan Gol Hydrological Station and Bayan Gol Hydrological Station to Toudaoguai Hydrological Station) for some periods exhibited relatively large errors (the relative mean deviations between measured and simulated values of $18 \%$ and $25 \%$, respectively). These errors are presumably related to the inability to accurately determine the quantity of aeolian sediment influx to the river reach and the inflow of water from the ten ephemeral tributaries. This study may provide some valuable insights into the numerical simulations of flow and sediment transport in large watersheds and also provide a useful model for the effective management of the NMRYR.
\end{abstract}

Keywords: numerical simulation; flow and sediment transport; 1-D flow \& sediment model; Yellow River

Citation: DOU Shentang, YU Xin, DU Heqiang, ZHANG Fangxiu. 2017. Numerical simulations of flow and sediment transport within the Ning-Meng reach of the Yellow River, northern China. Journal of Arid Land, 9(4): 591-608. doi: $10.1007 / \mathrm{s} 40333-017-0059-6$

\section{Introduction}

Flow and sediment (including suspended and bedload) transport within rivers are complex physical processes. In the simulations of flow and sediment transport, it is essential to understanding the responses of sediment movement to flow at different temporal and spatial scales (Merritt et al., 2003). A considerable number of models have been developed to simulate flow and sediment transport (e.g., Beasley et al., 1980; Fan, 1988; Laflen et al., 1991; Hanley et 
al., 1998; Viney et al., 2000; Rodi, 2006). In general, these models fall into four main categories: (1) empirical models; (2) conceptual models; (3) physical models; and (4) numerical hydrodynamic models (Merritt et al., 2003). Of the four categories, the numerical hydrodynamic models have the unique advantage of being easily adaptable to different physical domains. Furthermore, they are not subjected to distortion effects like physical models when simulating the flow conditions (e.g., identical Reynolds and Froude numbers, same length scale in the three directions, etc.) as those present in the field (Papanicolaou et al., 2008; Wu et al., 2012; Chen et al., 2013; Dou et al., 2014).

Over the past three decades, a large number of numerical hydrodynamic models were developed (Fan, 1988; Rodi, 2006), including flow and sediment transport models (Martins, 1989; Nakato, 1990; Onishi, 1994; Przedwojski et al., 1995; Spasojevic and Holly Jr, 2000). Broadly speaking, these models can be classified into three sub-categories on the basis of the dimensions: one-dimensional (1-D) models, two dimensional (2-D) models and three-dimensional (3-D) models (Papanicolaou et al., 2008). The 1-D models have been successfully used in many scientific researches since the early 1980s (Burkow and Griebel, 2016). Most of the 1-D models are formulated using a rectilinear coordinate system and the representative models include Mobile BED (Krishnappan, 1981), Iowa ALLUVIAL (Karim and Kennedy, 1982), CHARiage (Holly Jr et al., 1990), SEDIment COUPled (Holly Jr and Rahuel, 1990), and Steep Stream Sediment Transport 1D Model (Papanicolaou et al., 2004). In addition, there are a few 1-D models that are formulated using different types of coordinate systems and the representative models include FLUVIAL 11 (Chang, 1984), Generalized Stream Tube Model for Alluvial River Simulation (Molinas and Yang, 1986), and One-dimensional Transport with Inflow and Storage (Runkel and Broshears, 1991). It was widely reported that in the simulations of flow and sediment transport, the 1-D models could predict the basic hydrologic and geomorphic parameters associated with open-channel riverine conditions and the parameters include water surface elevation, section-averaged velocity, sediment concentration, degree of deposition or erosion, and channel bed deformation (Fang and Wang, 2000; Zhang et al., 2002; Wu et al., 2004; Termini, 2011; Luan and Jin, 2016). For example, Zhang et al. (2002) used a 1-D model to simulate the non-uniform sediment transport under unsteady flow conditions in the Yellow River. All in all, the 1-D models have the advantages of simple model structures, less computation redundancies, higher computational efficiency, etc. They are suitable to simulate the flow and sediment transport in large watersheds with complex flow and sediment conditions, such as the Yellow River.

The aim of this study was to apply a 1-D flow \& sediment model to simulate the flow and sediment transport within the Ning-Meng reach of the Yellow River (NMRYR). The model was developed by the Yellow River Institute of Hydraulic Research and was widely used to simulate hyper-concentrated or low- concentrated flow transport in the lower reach of the Yellow River (e.g., Liang et al., 1999; Chen et al., 2004; Ren et al., 2004). One obvious advantage of this model is that factors such as aeolian processes, reservoir operations, and others can be easily integrated into the model. Based on the complex flow and sediment conditions of the NMRYR and the openness of this 1-D model, we improved the model by considering more parameters/factors to increase the accuracy of flow and sediment transport simulations. Firstly, the flow and sediment characteristics (such as sediment concentration, sediment siltation, particle size distribution, etc.) within the NMRYR were considered. Secondly, the complex hydrologic and geomorphic characteristics within the NMRYR including tributary inflow, aeolian sediment supply, water diversions (intake), return of farmland irrigation to the river, and formation of in-channel bars at some confluences were also considered. These improvements would provide a practical reference for the developers of hydrodynamic models and would also provide a scientific reference for simulating the flow and sediment transport in other similar rivers. It is our hope that the simulated results would provide some useful references for controlling siltation within the NMRYR.

\section{Study area}

\subsection{Ning-Meng reach of the Yellow River (NMRYR)}

The studied NMRYR, extending from the Xiaheyan Hydrological Station in Ningxia Hui 
Autonomous Region to the Toudaoguai Hydrological Station in Inner Mongolia Autonomous Region, has a total length of $949.89 \mathrm{~km}$. In general, the NMRYR is a slow-flowing stream with low gradient. It was especially the case (i.e., low gradient) along the reach in Inner Mongolia where the gradient is close to that in the Yellow River Estuary (Qin, 2009). NMRYR receives aeolian sediment because it is within an alluvial plain located between the Ningxia Plain and the Inner Mongolian Plateau and the NMRYR crosses extended deserts, including the Hedong Sandy Land, Ulan Buh Desert, and Hobq Desert (Fig. 1). The ambient environment is characterized by a continental monsoonal climate with mean annual precipitation of 150-400 $\mathrm{mm}$. It should be noted that annual precipitation decreases from east to west, and about $75 \%-90 \%$ of annual total precipitation occurs during the period July-September. The annual average wind speed is 2.5-5.0 $\mathrm{m} / \mathrm{s}$ with the windy season from November to succeeding May. The daily maximum wind speed can reach up to $20 \mathrm{~m} / \mathrm{s}$ and the mean sandstorm occurrence is 19-22 d/a. Soil types in the watershed vary from desert aeolian sandy soil in the west to chestnut soil, loess soil, and cinnamon soil in the east.

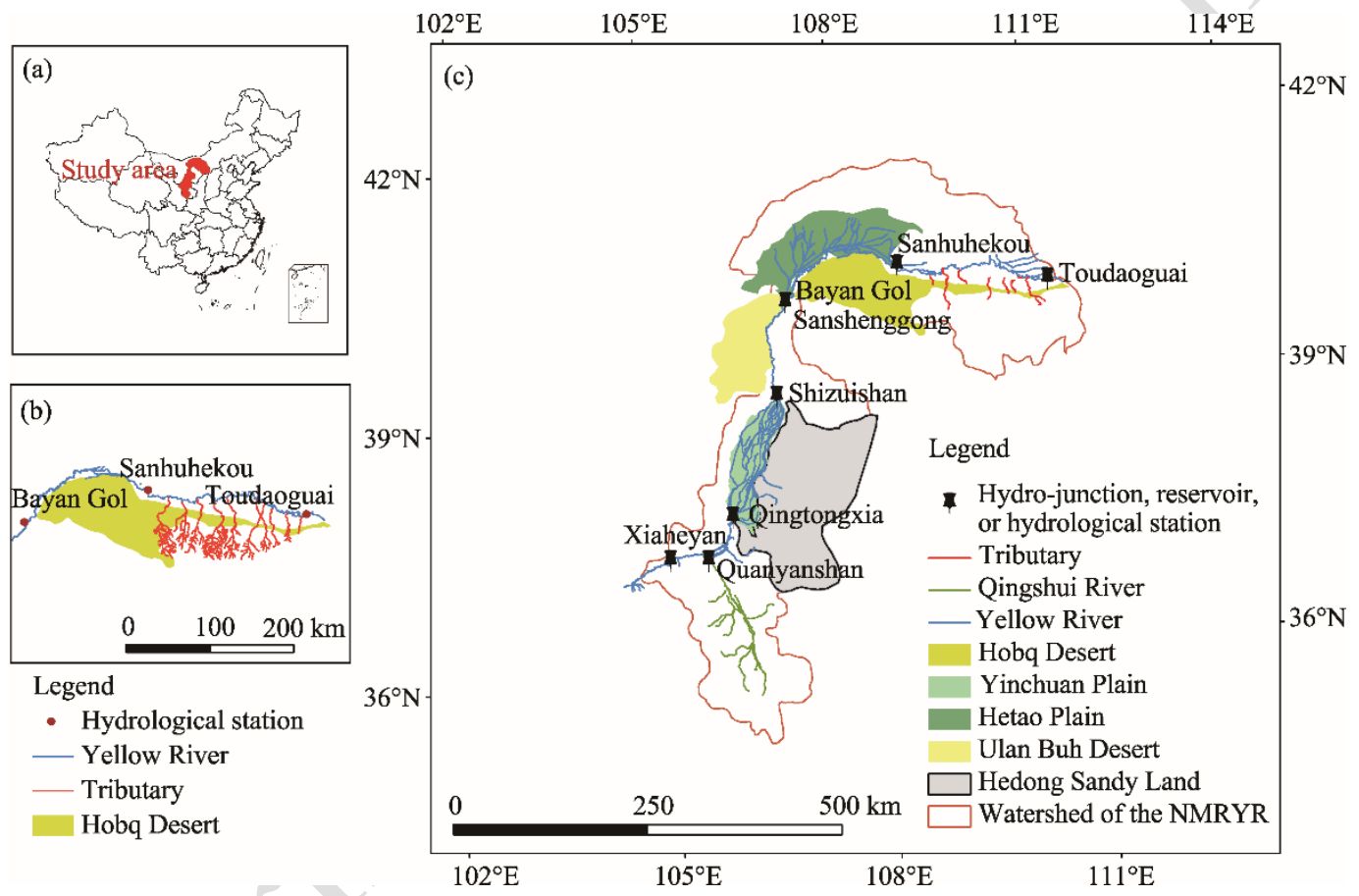

Fig. 1 (a) Location of the watershed of the Ning-Meng reach of the Yellow River (NMRYR), (b) sketch map of the upper region of the ten tributaries, and (c) sketch map of the whole watershed of the NMRYR. It should be noted that Sanshenggong Hydro-junction is situated several hundred meters upstream of the Bayan Gol Hydrological Station.

\subsection{Sub-reaches of the NMRYR}

The hydrological structure of the NMRYR is shown in Figure 2. We divided the NMRYR into three sub-reaches based on the occurrence of hydro-junction, reservoir, or hydrological station: Xiaheyan Hydrological Station to Qingtongxia Reservoir (X-Q), Qingtongxia Reservoir to Bayan Gol Hydrological Station (Q-B), and Bayan Gol Hydrological Station to Toudaoguai Hydrological Station (B-T). Characteristics of the three sub-reaches are shown in Table 1 (Qin, 2009).

\subsubsection{X-Q sub-reach}

The X-Q sub-reach has a total length of $119.2 \mathrm{~km}$. It should be noted that both tributary inflow and irrigation diversions were considered in the simulations of flow and sediment transport in this study. The most important tributary within this sub-reach is the Qingshui River whose runoff has 
been gauged at the Quanyanshan Hydrological Station (Fig. 1). Irrigation diversions along the $\mathrm{X}-\mathrm{Q}$ sub-reach are dominated by three canals, including the Tanglai Canal (diversion capacity of $450 \mathrm{~m}^{3} / \mathrm{s}$ ) located on the west side of the Yellow River, and the Qinhan Canal (diversion capacity of $115 \mathrm{~m}^{3} / \mathrm{s}$ ) and Donggao Canal (diversion capacity of $75 \mathrm{~m}^{3} / \mathrm{s}$ ) located on the east side of the Yellow River. All these three channels were considered in this study. Irrigation diversions primarily occur from April to June and also during November. According to the statistical (unpublished) data provided by the Yellow River Conservancy Commission, the total annual diversion of these three canals ranged from $6 \times 10^{9}$ to $7 \times 10^{9} \mathrm{~m}^{3}$ in $2000 \mathrm{~s}$, and the diversion from the Tanglai Canal exceeded $82 \%$ of the total diversion.

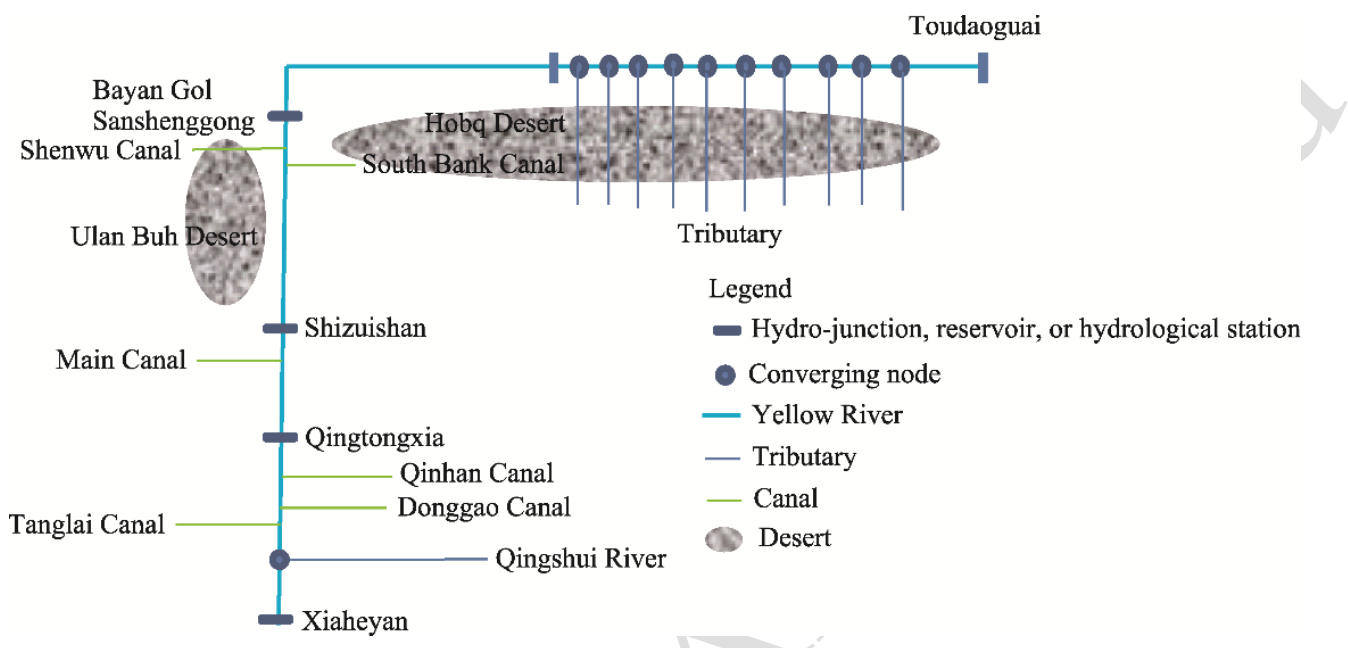

Fig. 2 Conceptual diagram of the basic hydrological structure of the NMRYR

Table 1 Characteristics of the NMRYR and its three sub-reaches (Qin, 2009)

\begin{tabular}{ccccc}
\hline & Length $(\mathrm{km})$ & $\begin{array}{c}\text { Number of } \\
\text { tributaries }\end{array}$ & $\begin{array}{c}\text { Number of } \\
\text { sections }\end{array}$ & $\begin{array}{c}\text { Average spacing between two adjacent } \\
\text { sections }(\mathrm{m})\end{array}$ \\
\hline NMRYR & 949.89 & 13 & 301 & 3200 \\
X-Q sub-reach & 119.20 & 1 & 52 & 2378 \\
Q-B sub-reach & 334.64 & 0 & 142 & 2352 \\
B-T sub-reach & 491.60 & 12 & 107 & 4595 \\
\hline
\end{tabular}

Note: NMRYR, Ning-Meng reach of the Yellow River; X-Q, Xiaheyan Hydrological Station to Qingtongxia Reservoir; Q-B, Qingtongxia Reservoir to Bayan Gol Hydrological Station; B-T, Bayan Gol Hydrological Station to Toudaoguai Hydrological Station.

\subsubsection{Q-B sub-reach}

The Q-B sub-reach has a total length of $334.64 \mathrm{~km}$. There are no significant tributaries along this sub-reach. Irrigation waters were mainly withdraw from the Main Canal, South Bank Canal, and Shenwu Canal. The total diversion of these three channels accounts for $28 \%$ of the total annual diversion within this sub-reach, and the total diverted suspended sediment of these three channels accounts for $\sim 27 \%$ of the total annual sediment load. From 1958 to 2001, the total diversion of the Q-B sub-reach varied from $5.07 \times 10^{9}$ to $6.93 \times 10^{9} \mathrm{~m}^{3}$, and the total diverted suspended sediment varied from $0.014 \times 10^{9}$ to $0.213 \times 10^{9}$ t. Moreover, the sediment siltation within the Q-B sub-reach is influenced by the direct (sand blown or dune migration into channels) and/or indirect (aeolian sediment influx to the Yellow River) entry of sediments from the surrounding deserts.

\subsubsection{B-T sub-reach}

The B-T sub-reach has a total length of $491.60 \mathrm{~km}$. It generally transits from a wandering channel to a meandering channel. Sediment siltation continuously increased and the channel sinuosity also increased after the integrated operation of the Longyangxia and Liujiaxia reservoirs. Thus, several segments of the B-T sub-reach became "suspended rivers" that increased the traverse gradient of the sub-reach. The upstream of the B-T sub-reach, extending from the Bayan Gol Hydrological 
Station to the Sanhuhekou Hydrological Station, has a total length of $216 \mathrm{~km}$, a sinuosity of 1.16, and a width/depth ratio $\left(B^{0.5} / H\right)$ of 5 . The downstream of the B-T sub-reach, extending from the Sanhuhekou Hydrological Station to the Toudaoguai Hydrological Station, has a total length of $300 \mathrm{~km}$, a sinuosity of 1.39 , and a width/depth ratio $\left(B^{0.5} / H\right)$ of 9 (Zhou et al., 2012). There are ten tributaries that discharge flow and sediment into the Yellow River and they are (from west to east): Maobula Gully, Burstai Gully, Heilai Gully, Xiliu Gully, Hantai Gully, Haoqing River, Hasila Gully, Muhar River, Dongliu Gully, and Husitai River. All these tributaries originate within the Erdos Plateau and are oriented approximately parallel to one another. The Erdos Plateau is underlain primarily by high erodible loose sandstone, leading to serious soil erosion and large quantities of eroded sediments into the ten tributaries. The total annual sediment siltation of the ten tributaries was relatively high in the study area, exceeded $25.6 \times 10^{6} \mathrm{t}$ during the period $1953-$ 2010.

In addition, wind erosion directly and/or indirectly delivers aeolian sediments to the B-T sub-reach. The combination of highly erodible strata within the watershed of the B-T sub-reach and the influx of large quantities of tributary and aeolian sediments to the B-T sub-reach has led to serious sediment deposition within the main channel, particularly the gently-sloped river channel (Hou, 1996; Zhao et al., 1999; Ta et al., 2003).

\section{Model}

To obtain accurate simulations of flow and sediment transport, we made some improvements on the 1-D model by taking into account the flow and sediment characteristics (including sediment concentration, sediment siltation, particle size distribution, etc.) and also the complex hydrological and geomorphic characteristics of the NMRYR (including tributary inflow, aeolian sediment supply, water diversions (intake), return of farmland irrigation, and the formation of in-channel bars at some confluences). During the simulating process, control conditions such as reservoir operations (including upstream water levels and discharge from reservoirs), influx water from tributaries, etc. within the $\mathrm{X}-\mathrm{Q}, \mathrm{Q}-\mathrm{B}$, and $\mathrm{B}-\mathrm{T}$ sub-reaches were presented in sequence from upstream to downstream. Flow and sediment characteristics were then systematically estimated using the 1-D model by combining the measured data collected from the hydrological stations in the upstream. It should be noted that we assumed that the flow and sediment siltation from the ten tributaries was one source for simplifying the 1-D model.

\subsection{Governing equations of the model}

In this study, the basic equations applied in the 1-D model to calculate the steady flow and sediment concentration included the flow continuity equation (Eq. 1), flow kinematic equation (Eq. 2), sediment continuity equation (suspended sediment convection-diffusion; Eq. 3), and riverbed deformation equation (Eq. 4) (Wang, 1996; Li and Shang, 1998; Zhang et al., 2003; Peng and Zhang, 2006).

$$
\begin{gathered}
\frac{\partial Q}{\partial x}=0, \\
\frac{\partial\left(Q^{2} / A\right)}{\partial x}=-g A\left(\frac{\partial Z}{\partial x}+S_{f}\right), \\
\frac{\partial}{\partial x}\left(Q S_{k}\right)=\alpha_{*_{k}} \omega_{k} B\left(S_{*_{k}}-S_{k}\right), \\
\gamma^{\prime} \frac{\partial Z_{b k}}{\partial t}=\alpha_{*_{k}} \omega_{k}\left(S_{k}-S_{*_{k}}\right),
\end{gathered}
$$

where, $Q$ is the flow $\left(\mathrm{m}^{3} / \mathrm{s}\right) ; x$ and $t$ are the transport distance and time of flow, respectively (in units of $\mathrm{m}$ and $\mathrm{s}$, respectively); $A$ is the cross-sectional flow area $\left(\mathrm{m}^{2}\right) ; g$ is the gravitational constant of acceleration $\left(\mathrm{m} / \mathrm{s}^{2}\right) ; Z$ is the water level $(\mathrm{m}) ; S_{f}$ is the friction slope, dimensionless; $S_{k}$ is the sectional sediment concentration of the $k^{\text {th }}$ group $\left(\mathrm{kg} / \mathrm{m}^{3}\right) ; S_{* k}$ is the section-averaged 
sediment transport capacity of the $k^{\text {th }}$ grade $\left(\mathrm{kg} / \mathrm{m}^{3}\right) ; \alpha_{* k}$ is the distribution coefficient of the equilibrium sediment concentration of the $k^{\text {th }}$ group; $\omega_{k}$ is the sediment settling velocity of the $k^{\text {th }}$ group $(\mathrm{m} / \mathrm{s}) ; B$ is the width of the water surface $(\mathrm{m}) ; \gamma^{\prime}$ is the dry density of the sediment $\left(\mathrm{kg} / \mathrm{m}^{3}\right)$; and $Z_{b k}$ is the elevation of the riverbed of the $k^{\text {th }}$ group $(\mathrm{m})$.

$S_{* k}$ can be calculated by Equation 5 (Zhang et al., 2003):

$$
S_{*_{k}}=2.5\left[\frac{\left(0.0022+S_{v}\right) U^{3}}{\kappa \frac{\gamma_{s}-\gamma_{m}}{\gamma_{m}} g h \omega_{s}} \ln \left(\frac{h}{6 D_{50}}\right)\right]^{0.62},
$$

where, $\gamma_{s}$ and $\gamma_{m}$ are the volume-weights of the sediment and the flow, respectively $\left(\mathrm{t} / \mathrm{m}^{3}\right) ; S_{v}$ and $\omega_{s}$ are the dynamic viscosity coefficient $\left((\mathrm{kg} \cdot \mathrm{s}) / \mathrm{m}^{2}\right)$ and the kinematic viscosity coefficient $\left(\mathrm{m}^{2} / \mathrm{s}\right)$ of clean water, respectively; $D_{50}$ is the median diameter of the riverbed sediment $(\mathrm{m})$; $U$ is the mean velocity of the flow within a given section $(\mathrm{m} / \mathrm{s}) ; h$ is the water depth of a given section $(\mathrm{m})$; and $\kappa$ is the Von Karmans constant of muddy water, which can be calculated using Equation 6.

$$
\kappa=0.4\left[1-4.2 \sqrt{S_{v}}\left(0.365-S_{v}\right)\right] .
$$

After simplified the sediment continuity equation (Eq. 3) and integrated the MacCormack algorithm (Ong and Knight, 1987), the discrete form of sediment continuity equation can be written as:

$$
S_{k, i+1}=S_{* k, i+1}+\left(S_{k, i}-S_{* k, i}\right) \mathrm{e}^{-\frac{\alpha \omega \Delta x}{Q}}-\mathrm{e}^{-\frac{\alpha \omega \Delta x}{Q}} \int_{0}^{\Delta x} \mathrm{e}^{-\frac{\alpha \omega \Delta x}{Q}} \frac{d S_{* k}}{d x} d x,
$$

where, $i$ and $i+1$ are the consecutive cross sections, and $i$ increases along the flow direction; $\alpha$ is the distribution coefficient of the equilibrium sediment concentration $\left(\mathrm{kg} / \mathrm{m}^{3}\right) ; \omega$ is the sediment settling velocity $(\mathrm{m} / \mathrm{s})$. This discrete equation (Eq. 7) can be applied to determine the specific sediment size fractions (intervals).

\subsection{Key parameters of the model}

The flow and sediment transport exhibits complex relationships within the NMRYR. For example, sediments from the ten tributaries exert influence on the flow, sediment concentration, sediment siltation, and riverbed evolution of the main channel. And, the influences are most pronounced at those sections where the ten tributaries enter into the B-T sub-reach. In addition to the influences of sediments from the ten tributaries, other factors including aeolian sediment influx to the NMRYR, tributary inflow, irrigation diversions, and the constructed hydro-junction and reservoir along the NMRYR also exert influences the flow and sediment transport within the NMRYR. Therefore, these factors were considered in the 1-D model.

\subsubsection{Aeolian sediment influx to the NMRYR}

The Hedong Sandy Land, Ulan Buh Desert and Hobq Desert are important sediment sources to the NMRYR. Thus, aeolian sediment was considered in the 1-D model. The quantities of aeolian sediment influx to the NMRYR were calculated using the Revised Wind Erosion Equation (RWEQ) developed by the United States Department of Agriculture (Fryrear et al., 1998) and the Integrated Wind-Erosion Modelling System (IWEMS) proposed by Shao (2001). A more detailed discussion about how to calculate the quantities of aeolian sediments can be found in Du et al. (2015).

\subsubsection{Tributary inflow and irrigation diversions}

In this study, the tributary inflow and irrigation diversions were added to the governing equations to reflect the complex (and abrupt) changes of flow and sediment conditions along the NMRYR. With regards to the inflow from the ten tributaries and the diversions from the irrigation channels, the flow continuity equation (Eq. 1) can be converted as follows:

$$
\frac{\partial Q}{\partial x}=q_{l}
$$


where, $q_{l}$ is the change in flow per unit length, and $q_{l} \geq 0$ means tributary inflow occurring and $q_{l}<0$ means irrigation diversions occurring. The calculation of change in flow per unit length needs a modification in the sediment continuity equation (Eq. 3), and the equation can be modified as:

$$
\frac{\partial}{\partial x}\left(Q S_{k}\right)=\alpha_{* k} \omega_{k} B\left(S_{* k}-S_{k}\right)+q_{l s, k},
$$

where, $q_{l s, k}$ is the tributary inflow of the $k^{\text {th }}$ group sediment $\left(\mathrm{m}^{3} /(\mathrm{s} \cdot \mathrm{m})\right)$. It should be mentioned that the flow acts as a carrier in the processing of sediment diversion or supply, so the left term of Equation 9 cannot equal to 0 . In this situation, Equation 9 can be expressed as:

$$
\frac{\partial S_{k}}{\partial x}+\frac{1}{Q}\left(\frac{\partial Q}{\partial x}+\alpha B \omega_{k}\right) S_{k}=\frac{1}{Q}\left(q_{s, k}+\alpha B \omega_{k} S_{*_{k}}\right) .
$$

The analytical solution of sectional sediment concentration can be expressed as:

$$
S_{k, i+1}=S_{k, i} e^{-\int_{0}^{\Delta x} \frac{1}{Q}\left(q_{l}+\alpha B \omega\right) d x}+e^{-\int \frac{1}{Q}\left(q_{l}+\alpha B \omega\right) d x} \int_{0}^{\Delta x} \frac{1}{Q}\left(q_{l s, k}+\alpha B \omega S_{*}\right) \mathrm{e}^{\int \frac{1}{Q}\left(q_{l}+\alpha B \omega\right) d x} d x .
$$

The parameters $\partial Q / \partial x$ and $q_{l s, k}$ are equal to 0 when there is no flow or sediment diversions (inflow). Thus, Equation 11 equals to Equation 7. Furthermore, the scouring and siltation thickness of each sand group (fraction) can be calculated using the Equation 4 and Equation 11.

\subsubsection{Hydro-junction and reservoir}

The operations of hydro-junction and reservoir can influence the flow and sediment transport. In addition, the operation of hydro-junction or reservoir exhibits a discontinuous flow in the upstream and downstream of the hydro-junction or reservoir (Fig. 3). Therefore, the discontinuous water level should be considered in the simulations.

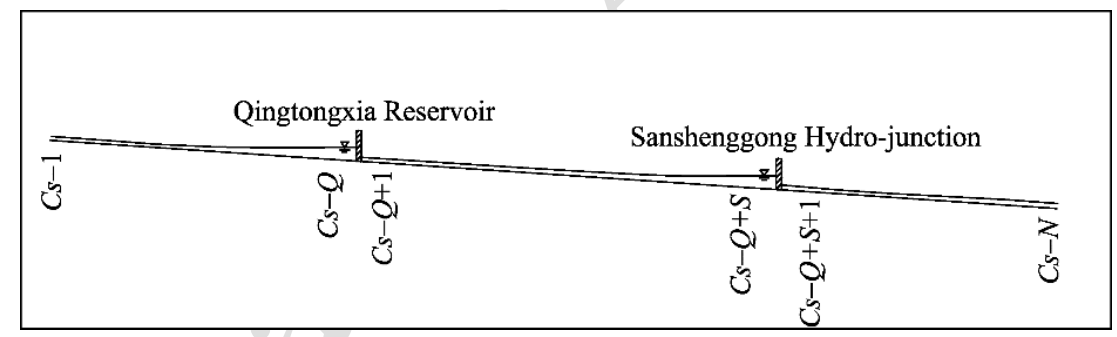

Fig. 3 Schematic diagram of discontinuous flow impacted by the Qingtongxia Reservoir and Sanshenggong Hydro-junction. $C s$, the serial number of cross sections; $C s-1$, the $1^{\text {st }}$ cross section above the Qingtongxia Reservoir; $C s-Q$, the $Q^{\text {th }}$ cross section, which is the last section above the Qingtongxia Reservoir; $C s-Q+1$, the $1^{\text {st }}$ section below the Qingtongxia Reservoir; $C s-Q+S$, the $(Q+S)^{\text {th }}$ cross section, which is the last section above the Sanshenggong Hydro-junction; $C s-Q+S+1$, the $1^{\text {st }}$ cross section below the Sanshenggong Hydro-junction; and $C s-N$, the $N^{\text {th }}$ cross section, which is the number of cross sections from the inlet to the outlet of the NMRYR.

Based on the operations of the Qingtongxia Reservoir and Sanshenggong Hydro-junction, we determined the flow from the reservoir or hydro-junction $\left(Q_{\text {out }}\right)$, water level upstream the dam $(Z)$, and water storage of the reservoir or hydro-junction $(W)$ by investigating the reservoir (hydro-junction) inflow $\left(Q_{\text {in }}\right)$ and sediment concentration $\left(S_{\text {in }}\right)$. Subsequently, the water level at every section can be calculated using an iteration formula derived from Equation 12:

$$
Z_{i}=Z_{i+1}+\Delta X \bar{J}+\frac{\left(\frac{Q^{2}}{A}\right)_{i+1}-\left(\frac{Q^{2}}{A}\right)_{i}}{g \bar{A}}
$$

where, $i$ and $i+1$ are the consecutive cross sections; $\Delta X$ is the distance from $i^{\text {th }}$ section to $(i+1)^{\text {th }}$ section $(\mathrm{m}) ; \bar{J}$ is the gradient of the river bed, which is dimensionless. 


\subsection{Data collection}

\subsubsection{X-Q sub-reach}

The simulations of flow and sediment transport within the X-Q sub-reach included the inflow water and sediments from the Qingshui River and the diversion from the Tanglai Channel. Control conditions within the X-Q sub-reach were based on the observed water level in the upstream of the reservoir from 2001 to 2012. The channel dimensions used in the simulations were based on the cross-section data collected in 2002. The data of flow, sediment concentration, and sediment grading (size distribution) in the upstream and downstream of the X-Q sub-reach were collected from the Xiaheyan Hydrological Station and the Qingtongxia Reservoir, respectively; the data of the Qingshui River (tributary) were obtained from the Quanyanshan Hydrological Station; and the data of irrigation diversions were provided by the Division Management Bureau that attached to the Yellow River Conservancy Commission.

\subsubsection{Q-B sub-reach}

The simulations of flow and sediment transport within the Q-B sub-reach included the aeolian sediments from the Ulan Buh Desert and the diversions of flow from the Main Canal, South Bank Canal, and Shenwu Canal. The Qingtongxia Reservoir, Shizuishan Hydrological Station, Sanshenggong Hydro-junction, and Bayan Gol Hydrological Station are located along the Q-B sub-reach. Control conditions such as inflow discharge, sediment concentration, sediment gradation, reservoir operation mode, etc. within the Q-B sub-reach were based on the measured hydrograph in the upstream of the Sanshenggong Hydro-junction from 2001 to 2012. The river boundary used in the simulations was based on the measured cross-section data collected in 2002 . The data of flow, sediment concentration, and sediment grading (size distribution) in the upstream and downstream of the Q-B sub-reach were collected from the Qingtongxia Reservoir and the Sanshenggong Hydro-junction, respectively. The data of irrigation diversions from 2001 to 2012 were provided by the Division Management Bureau that is a part of the Yellow River Conservancy Commission. It should be noted that the return of irrigation water from the Qiongtongxia irrigated area to the river was considered in the simulations while the ongoing construction of Haibowan Reservoir was ignored.

\subsubsection{B-T sub-reach}

The simulations of flow and sediment transport within the B-T sub-reach included the inflow water and sediments from the ten tributaries. Several hydrological stations are located along the B-T sub-reach, including the Bayan Gol Hydrological Station, Sanhuhekou Hydrological Station, and Toudaoguai Hydrological Station. Control conditions such as inflow discharge, sediment concentration, sediment gradation, reservoir operation mode, etc. within the B-T sub-reach were based on the measured hydrograph in the upstream of the Toudaoguai Hydrological Station from 2001 to 2012. The river boundary used in the simulations was based on the measured cross-section data collected in 2002. The data of flow, sediment concentration, and sediment grading (size distribution) were obtained from the Bayan Gol Hydrological Station; and the data of inflow water and sediments discharged from the ten tributaries were obtained from the Yellow River Conservancy Commission.

\subsection{Evaluation methods of the model}

In this study, two statistical parameters (root mean square error (RMSE) and relative mean deviation $(R M D)$ ) were used to evaluate the performance of the model. They were computed as criteria for goodness-of-fit between the measured and simulated values.

The RMSE is defined as follows (Thomann, 1982):

$$
R M S E=\left(\frac{\sum_{i=1}^{n}\left(M_{i}-S_{i}\right)}{n}\right)^{1 / 2} \text {, }
$$


where, $M_{i}$ and $S_{i}$ are the measured and simulated values for the $i^{\text {th }}$ pair, respectively; and $n$ is the total number of pairs. The smaller the RMSE, the higher the performance of the model (the simulated values being closing to the observed values).

The $R M D$ can be calculated by the following equation (Yen, 1993):

$$
R M D=\frac{\sum_{i=1}^{n}\left|M_{i}-S_{i}\right|}{\sum_{i=1}^{n} M_{i}} \times 100 \% .
$$

The smaller the absolute value of $R M D$, the higher performance of the model.

\section{Results}

The flow and sediment transport from 2001 to 2012 within the NMRYR were simulated using the 1-D numerical simulation model. It should be noted that we selected a representative period, i.e., the flood period (1 July to 31 October) in 2012 (with an extraordinary flood occurring), to display the simulated results of flow and sediment concentration because the variations of them during this period were large and obvious. The extraordinary flood occurred in 2012 was the largest flood event since 1989 with the longest lasting period and the largest peak discharge. According to the data collected from the hydrological stations along the NMRYR, there were at least 38 days with the daily average discharge higher than $2000 \mathrm{~m}^{3} / \mathrm{s}$.

\subsection{X-Q sub-reach}

The flow and sediment concentration within the X-Q sub-reach (including 24 cross-sections) were simulated. It should be pointed out that we selected the results of Qingtongxia Reservoir to verify the performance of the model because only this reservoir had the measured data. As shown in Figure 4, the measured and simulated values of flow and sediment concentration were very similar. The largest RMSE values of flow and sediment concentration between the measured and simulated values were less than $300 \mathrm{~m}^{3} / \mathrm{s}$ and $10 \mathrm{~kg} / \mathrm{m}^{3}$, respectively. The $R M D$ of sediment concentration (15\%) between the measured and simulated values was larger than that of flow (5\%), which could be attributable to the following two causes. First, the precise sediment data associated with the irrigation process (including the irrigation diversion and the return of irrigation water to the river) were lack. Second, sediments in the Qingshui River exhibited large variations during the flood period, which may increase the simulation error of sediment concentration within the main stream of the X-Q sub-reach.

Sediment siltation during the period 2001-2012 was simulated using the 1-D model. As shown in Figure 5, the trends of measured and simulated sediment siltation amounts within the X-Q sub-reach were consistent with an exception of 2011, in which slight siltation was measured but slight erosion was observed by simulated data. The RMSE and RMD of sediment siltation during the period 2001 and 2012 were less than $2.95 \times 10^{6} \mathrm{t}$ and $18 \%$, respectively.

\subsection{Q-B sub-reach}

We selected data of Qingtongxia Reservoir, Shizuishan Hydrological Station and Bayan Gol Hydrological Station to demonstrate the simulated results (Fig. 6). It seems that the correspondence between the peak values of flow and the peak values of sediment concentration for the Qingtongxia Reservoir, Shizuishan Hydrological Station and Bayan Gol Hydrological Station is acceptably reasonable. We infer that the flow at the Bayan Gol Hydrological Station is impacted by the regulation of Sanshenggong Hydro-junction (several hundred meters upstream of the Bayan Gol Hydrological Station). More specifically, flow data at the Bayan Gol Hydrological Station were all lower than those at the Shizuishan Hydrological Station (Fig. 6a).

To further validate the simulated results, we compared the measured and simulated flow and sediment concentration during the flood period of 2012 (1 July to 31 October) at the Bayan Gol Hydrological Station (Fig. 7). The RMSE values of flow and sediment concentration between the measured and simulated values were less than $200 \mathrm{~m}^{3} / \mathrm{s}$ and $0.7 \mathrm{~kg} / \mathrm{m}^{3}$, respectively; and the $R M D$ 
values were less than $8 \%$ and $18 \%$, respectively. Thus, the flow appeared to be satisfactorily simulated within the Q-B sub-reach. The $R M D$ of sediment concentration between the measured and simulated values was much higher than that of flow. The larger error of the sediment concentration may be due to the influx of aeolian sediments from the Ulan Buh Desert, which can impact sediment siltation along this sub-reach. As shown in Figure 6, sediment concentrations at the Bayan Gol Hydrological Station were larger than those at the Shizuishan Hydrological Station for some time periods, suggesting that aeolian sediment was supplied to the river reach between the Shizuishan Hydrological Station and the Bayan Gol Hydrological Station. Although we added a simulated module that calculated the quantity of aeolian sediment influx to the Yellow River, the module cannot compute bank collapse by mass wasting processes (Du et al., 2014). It should be noted that even though the volume of bank collapse was not large, it could impact the sediment concentration. Furthermore, the Bayan Gol Hydrological Station is located several hundred meters downstream of the Sanshenggong Hydro-junction, thus the discharged flow from the Sanshenggong Hydro-junction may carry sediments to the Bayan Gol Hydrological Station, increasing the sediment concentration at the Bayan Gol Hydrological Station.
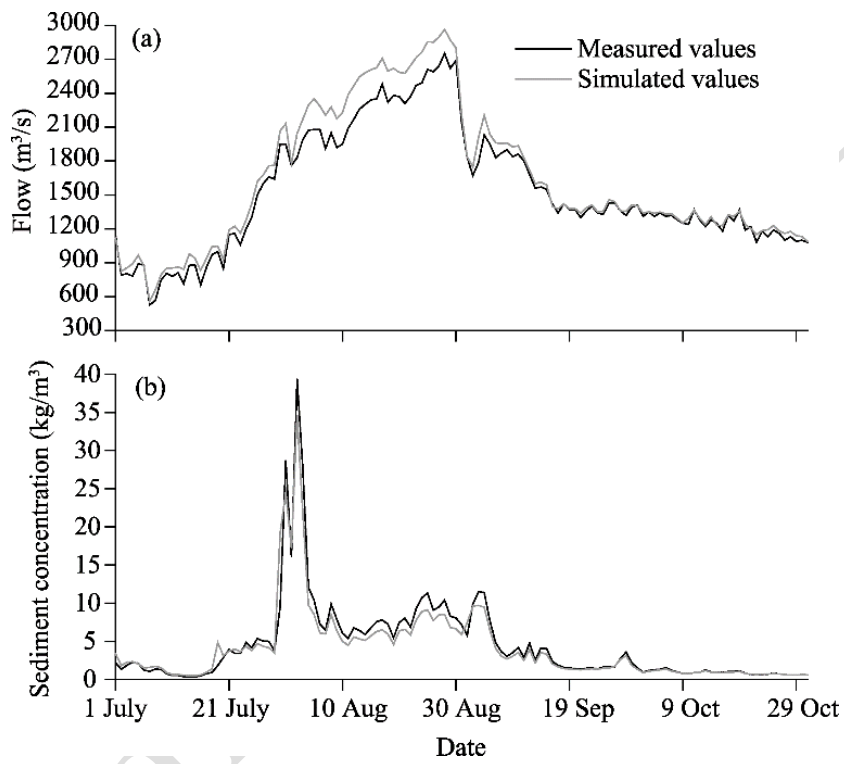

Fig. 4 Comparison of measured and simulated flow (a) and sediment concentration (b) during the flood period of 2012 (1 July to 31 October) at the Qingtongxia Reservoir within the X-Q (Xiaheyan Hydrological Station to Qingtongxia Reservoir) sub-reach

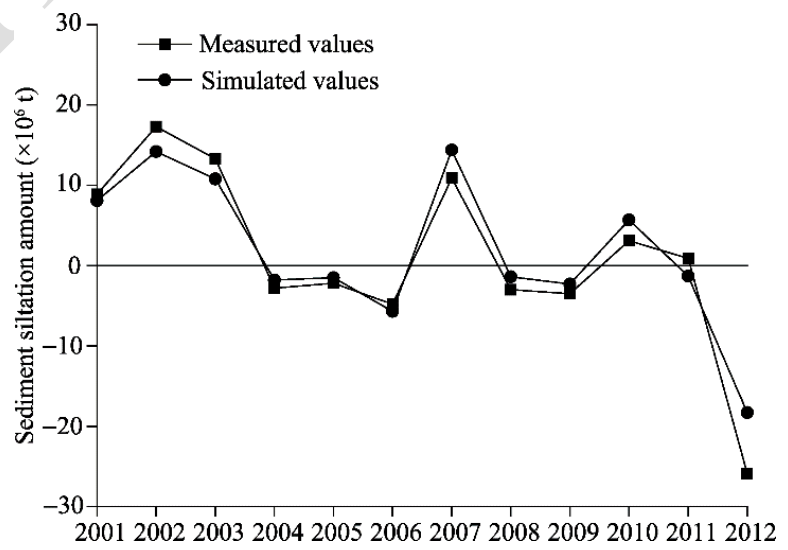

Fig. 5 Comparison of measured and simulated sediment siltation amounts from 2001 to 2012 within the X-Q sub-reach. It should be noted that positive value denotes sediment siltation while negative value denotes sediment erosion. 

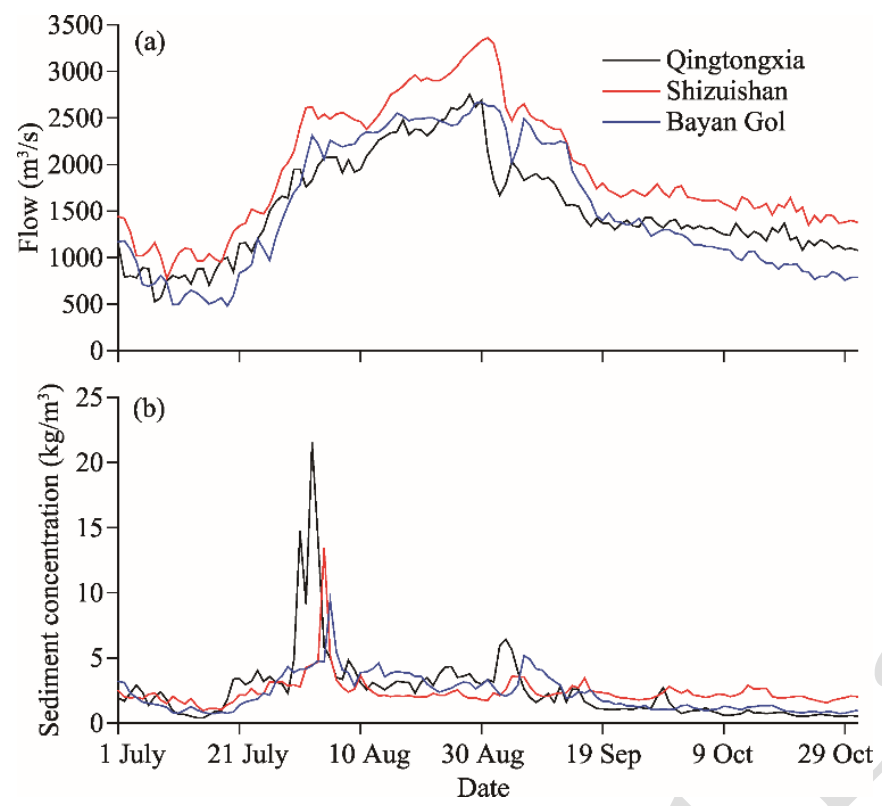

Fig. 6 Simulated flow (a) and sediment concentration (b) during the flood period of 2012 (1 July to 31 October) at the Qingtongxia Reservoir, Shizuishan Hydrological Station and Bayan Gol Hydrological Station within the Q-B (Qingtongxia Reservoir to Bayan Gol Hydrological Station) sub-reach

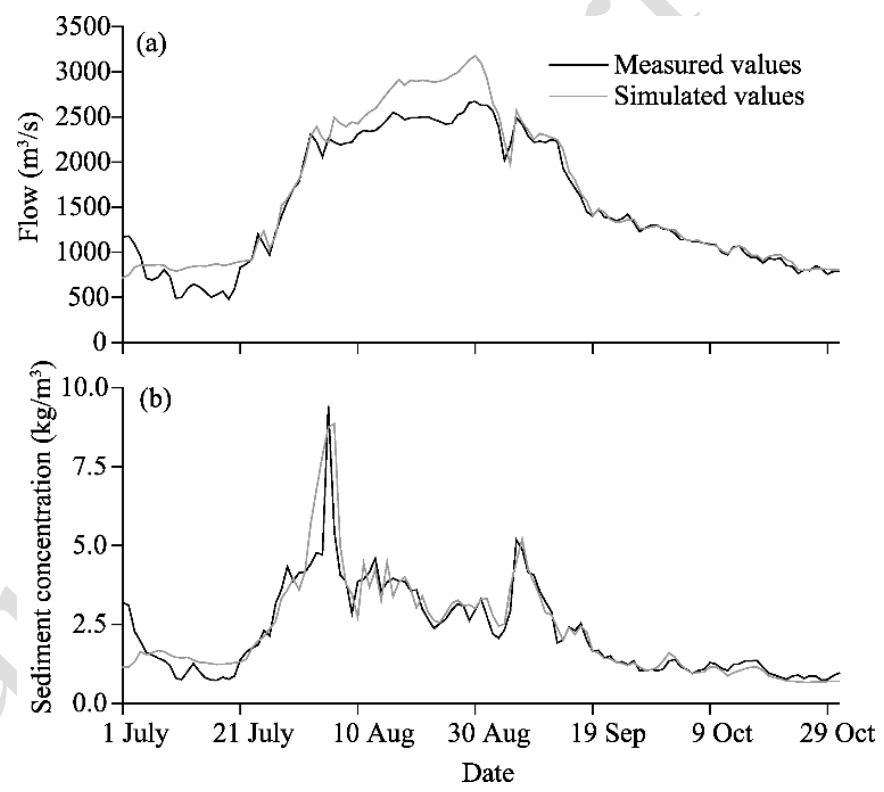

Fig. 7 Comparison of measured and simulated flow (a) and sediment concentration (b) during the flood period of 2012 (1 July to 31 October) at the Bayan Hydrological Station within the Q-B sub-reach

Sediment siltation during the period 2001-2012 was simulated using the 1-D model (Fig. 8). The patterns of measured and simulated sediment siltation amounts from 2001 to 2012 were similar and the amounts of simulated and measured siltation/erosion were approximately equal. The RMSE of sediment siltation amount between the measured and simulated values was $4.61 \times 10^{6} \mathrm{t}$ and the $R M D$ values were all less than $19 \%$ during the period 2001-2012. All in all, the model could effectively simulate sediment siltation within the Q-B sub-reach.

\subsection{B-T sub-reach}

We selected data of Bayan Gol Hydrological Station, Sanhuhekou Hydrological Station and Toudaoguai Hydrological Station to demonstrate the simulated results (Fig. 9). Figure 9a shows 
that the flow curves within the river reach from the Bayan Gol Hydrological Station to the Toudaoguai Hydrological Station were smooth. The flood peak took two days to move from the Bayan Gol Hydrological Station to the Sanhuhekou Hydrological Station, and the peak values of the flow continuously increased downstream as a result of inflow additions from the ten tributaries. The result suggests that the simulated flow is reasonable and stable. The peak in sediment concentration also took two days to move from the Bayan Gol Hydrological Station to the Sanhuhekou Hydrological Station (Fig. 9b), being consistent with the transport time lag of flow. In addition, during the flood period of 2012, the river reach from the Bayan Gol Hydrological Station to the Sanhuhekou Hydrological Station underwent a period of scour as the measured sediment concentrations at the Bayan Gol Hydrological Station were lower than those at the Sanhuhekou Hydrological Station. Furthermore, sediment deposition along the river reach from the Sanhuhekou Hydrological Station to the Toudaoguai Hydrological Station was likely resulted from the fact that the sediment concentrations at the Sanhuhekou Hydrological Station were higher than those at the Toudaoguai Hydrological Station.

To further validate the simulated results, we compared the measured and simulated flow and sediment concentration during the flood period of 2012 (1 July to 31 October) at the Toudaoguai Hydrological Station (Fig. 10). The RMSE values of flow and sediment concentration between the measured and simulated values during the flood period of 2012 were $58.622 \mathrm{~m}^{3} / \mathrm{s}$ and $0.54 \mathrm{~kg} / \mathrm{m}^{3}$, respectively; and the $R M D$ values were less than $8 \%$ and $25 \%$, respectively. The $R M D$ of sediment concentration between the measured and simulated values was much higher than that of flow. The larger error of sediment concentration may be caused by the hyper-concentrated flow from the ten tributaries.

Sediment siltation during the period 2001-2012 was simulated (Fig. 11). The simulated results show that the B-T sub-reach generally exhibited sediment deposition before 2009, with the largest episode of sediment siltation occurred in 2003, in which floods within the ten tributaries occurred in July. According to the data from the Tugerige Hydrological Station (on the Maobula Gully) and Longtouguai Hydrological Station (on the Xiliugou Gully), the annual water yields from the Maobula Gully and Xiliugou Gully were $40.7 \times 10^{6}$ and $51.0 \times 10^{6} \mathrm{~m}^{3}$, respectively; and the sediment loads were $10.7 \times 10^{6}$ and $8.0 \times 10^{6} \mathrm{t}$, respectively. The influx of such a large mass of sediments to the Yellow River likely caused serious sediment siltation along the B-T sub-reach. As shown in Figure 11, minor scouring occurred after 2009, especially in 2010 when the amount of erosion was up to $17.0 \times 10^{6} \mathrm{t}$, in spite of the fact that the water yield for the year was not the largest during the entire simulated time period. Furthermore, the RMSE and RMD of sediment siltation between the measured and simulated values were less than $5.2 \times 10^{6} \mathrm{t}$ and $23 \%$, respectively. In total, the simulated values were similar to the measured values.

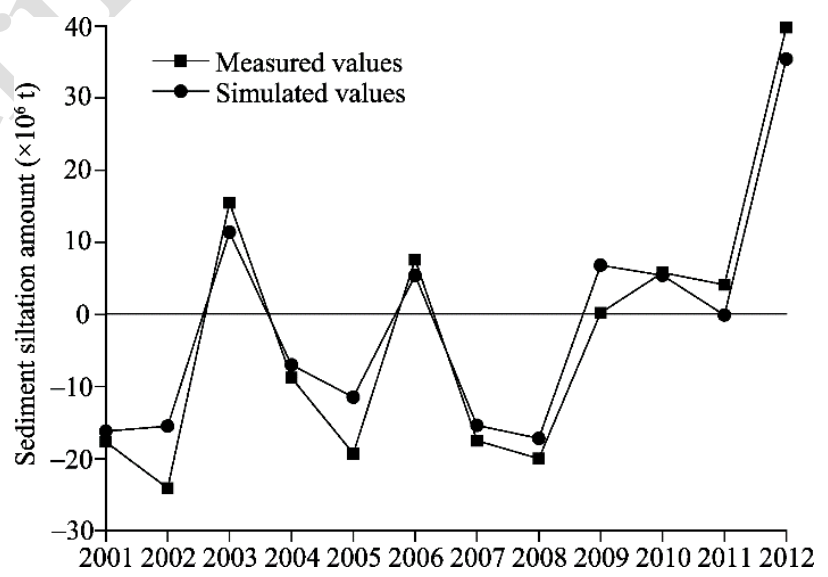

Fig. 8 Comparison of measured and simulated sediment siltation amounts from 2001 to 2012 along the Q-B sub-reach. It should be noted that positive value denotes sediment siltation while negative value denotes sediment erosion. 


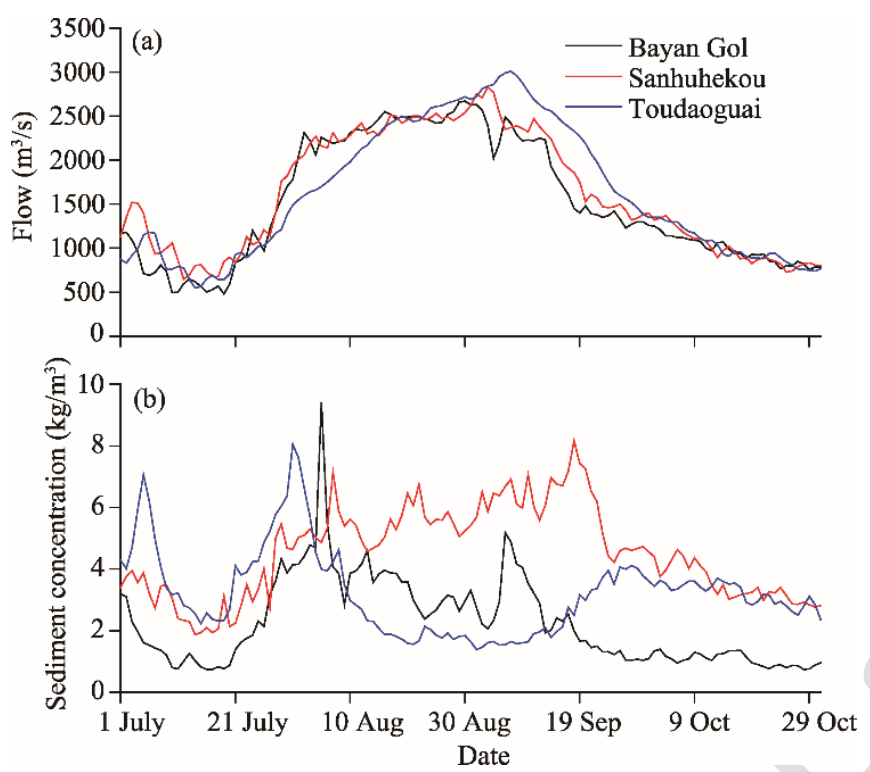

Fig. 9 Simulated flow (a) and sediment concentration (b) during the flood period of 2012 (1 July to 31 October) at the Bayan Gol Hydrological Station, Sanhuhekou Hydrological Station, and Toudaoguai Hydrological Station within the B-T (Bayan Gol Hydrological Station to Toudaoguai Hydrological Station) sub-reach
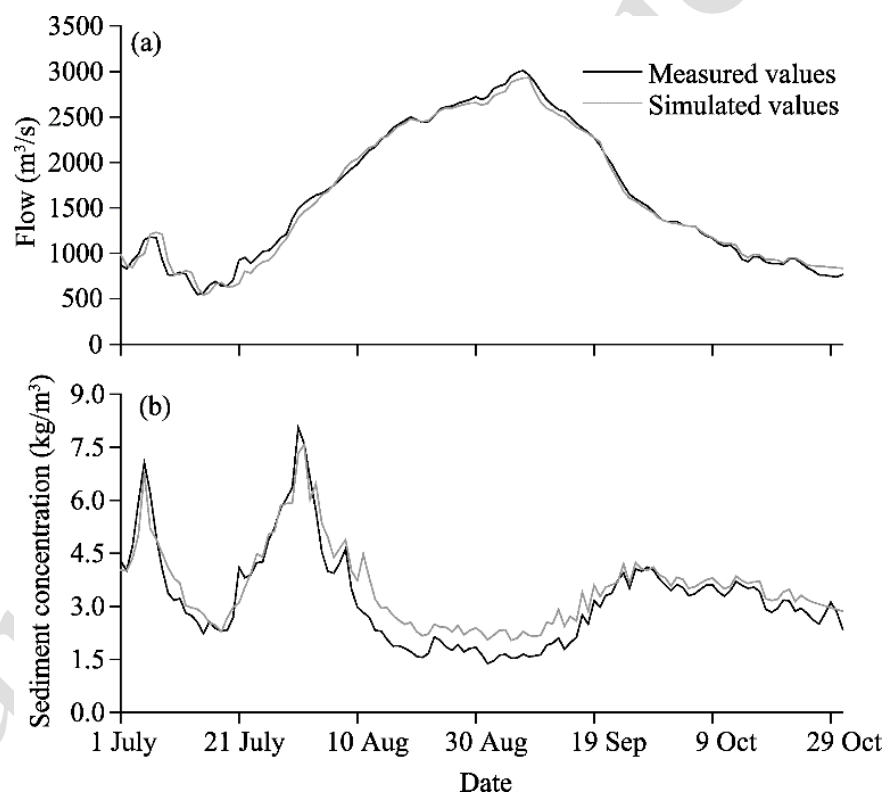

Fig. 10 Comparison of measured and simulated flow (a) and sediment concentration (b) during the flood period of 2012 (1 July to 31 October) at the Toudaoguai Hydrological Station within the B-T sub-reach

\section{Discussion}

Modeling the NMRYR is difficult because of its inherent natural and man-made complexities in physical and hydrological conditions. For examples, the reach traverses several landforms types and the stream patterns of the reach are complex. Not only does the supply of sediments to the channels need to be considered in the simulations but also the sediments from tributaries and aeolian sediments from the surrounding deserts should be considered (Ta et al., 2003; Du et al., 2015). Furthermore, the hydrology of the watershed is not only affected by agricultural irrigation 


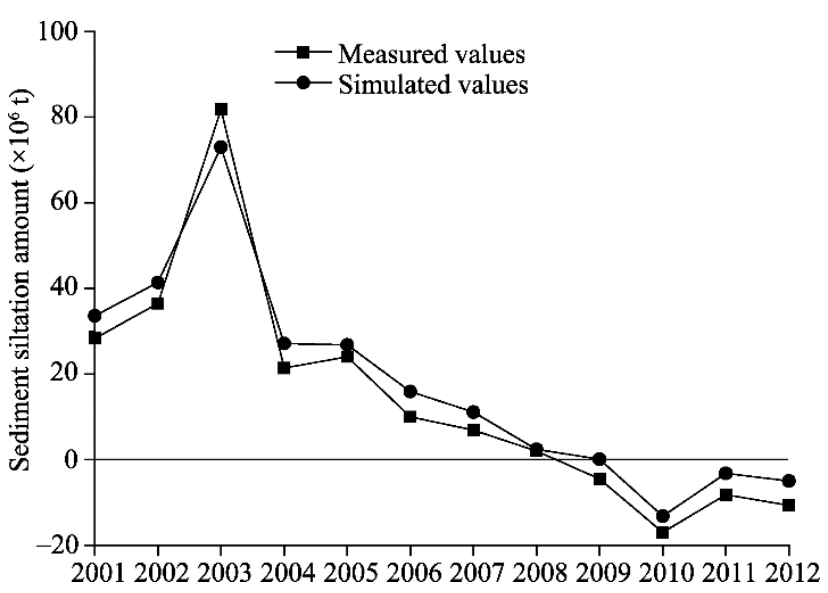

Fig. 11 Comparison of measured and simulated sediment siltation amounts from 2001 to 2012 along the B-T sub-reach. It should be noted that positive value denotes sediment siltation while negative value denotes sediment erosion.

but also by the changes in the water surface caused by hydro-junctions (reservoirs) (Su et al., 2015). When these complexities are fully considered in the simulations, the simplified approach used in this study could obtain satisfactory results.

Although we considered the processes and factors that could affect the flow and sediment transport as comprehensively as we could, the simulated results still exhibited deviations compared to the measured values, with the relative deviation of sediment concentration being higher than that of flow. Thus, the natural flood process of 2012 was analyzed to comprehensively understand the causes of the deviations. The flood in 2012 was the large runoff event since 1989; and the peak flows measured at the Xiaheyan Hydrological Station, Qingtongxia Reservoir, Shizuishan Hydrological Station, Bayan Gol Hydrological Station, Sanhuhekou Hydrological Station and Toudaoguai Hydrological Station were 3360, 3050, 3390, 2710,2840 and $3030 \mathrm{~m}^{3} / \mathrm{s}$, respectively.

We speculate that the three characteristics of the flood in 2012 may be the main causes of the errors. First, the water yield within the NMRYR is imbalance during the period because of the diversion and return of irrigation water, lateral tributary inflow, and water loss during transport. According to the data for 2012 collected from the Yellow River Conservancy Commission, the cumulative discharge of the Xiaheyan Hydrological Station was $14.9 \times 10^{9} \mathrm{~m}^{3}$ and the total diversion of the Hedong Main Canal and Hexi Main Canal was $1.6 \times 10^{9} \mathrm{~m}^{3}$. The cumulative discharge of the Qingtongxia Reservoir was $12.1 \times 10^{9} \mathrm{~m}^{3}$ and the total diversion of the Shenwu Main Canal, South Main Canal, and Main Canal distributed between the Shizuishan Hydrological Station and the Bayan Gol Hydrological Station was $1.5 \times 10^{9} \mathrm{~m}^{3}$. The cumulative discharge values of the Bayan Gol Hydrological Station, Sanhuhekou Hydrological Station, and Toudaoguai Hydrological Station were $13.0 \times 10^{9}, 13.6 \times 10^{9}$, and $13.8 \times 10^{9} \mathrm{~m}^{3}$, respectively. Second, during the flood period in 2012, channel erosion is the main process along the NMRYR. Given the sectional areas of deposition and erosion and the average flow velocities, we estimated the flow capacity of the main channel and all hydrological stations within the NMRYR. During the flood period in 2012, flow capacity of the main channel at the Bayan Gol Hydrological Station and Sanhuhekou Hydrological Station increased more than $400 \mathrm{~m}^{3} / \mathrm{s}$; and flow capacity at all the other stations also increased. In addition, the average water level between the Bayan Gol Hydrological Station and the Sanhuhekou Hydrological Station decreased by $0.355 \mathrm{~m}$, while the simulated erosion within this river reach was $68.4 \times 10^{6}$ t. Third, flood in 2012 caused obvious variations in channel morphology/regime. By comparing river sections before and after this flood, we found that the main channel between the Bayan Gol Hydrological Station and the Sanhuhekou Hydrological Station (meandering reach) exhibited the largest-amplitude variations, with the maximum swing amplitude reaching up to $200 \mathrm{~m}$; followed by the river reach between the Sanhuhekou 
Hydrological Station and the Zhaojunfen Hydrological Station (transitional reach), with the maximum swing amplitude of $130 \mathrm{~m}$ (from wandering to meandering). The swing amplitude within the river reach between the Zhaojunfen Hydrological Station and the Toudaoguai Hydrological Station (meandering channel) was less than $55 \mathrm{~m}$.

All in all, water imbalance, severe erosion, and variations in channel morphology/regime significantly increased the difficulty of simulating flow and sediment transport. Furthermore, there are some additional minor problems that would cause uncertainties in the simulations. For example, errors associated with simulated sediment concentrations within the Q-B sub-reach were relatively large (in comparison to the other sub-reaches), presumably because of the influx of aeolian sediments from the Ulan Buh Desert and the impact of flood discharge from the Sanshenggong Hydro-junction on bed sediment transport. There were many studies attempted to determine or estimate the sources and quantity of aeolian sediment influx to the Yellow River by the methods of geochemical elements analysis, particle size analysis, sediment budgets, etc. (e.g., Yang et al., 1988; Jia and Wang, 2011; Jia et al., 2011; Ta et al., 2013). However, the specific quantity of aeolian sediment influx to the Yellow River has not been agreed upon. In this study, although two models (IWEMS and RWEQ) were used to calculate the quantity of aeolian sediment influx to the NMRYR, they could only calculate the aeolian deposition associated with the movement of sands. The input of aeolian sediments associated with the processes of bank collapse was not included in the models (Du et al., 2014), which was most likely to impact the simulated sediment concentration results. The amount of bank collapse is also difficult to be determined, generally due to the lack of observational data (Yao et al., 2011). In this study, we attempted to simulate the process of bank collapse, but the process is very complex and requires more data that are not available (Yu et al., 2013). More specifically, the bank erosion caused by stream flow often increases the slope of the dunes that cover alluvial bank materials, and when the slope is larger than the angle of sediment repose, the dunes collapse into the river (Han et al., 2009). At present, we cannot (1) identify the angles of sediment repose of different surfaces that are effected by vegetation cover, soil structure, etc., and (2) predict the changes in bank slopes (angles) during an event. In future works, we intend to increase our observations of bank collapse along the NMRYR to provide more basic data for numerical simulations.

Apart from the Q-B sub-reach, the simulated results of sediment concentration along the B-T sub-reach were relatively poor, presumably because of the input of hyper-concentrated flows from the ten tributaries that originate from the Erdos Plateau. The ten tributaries are all ephemeral rivers and are distributed approximately parallel to one another. The upper regions of the ten tributaries are underlain by loose sandstone with high erodibility. The annual precipitation is not high but is associated with short, intense rainstorms that produce hyper-concentrated flow (Xu, 2013). Although we considered the supply of sediments from the tributaries in the simulations, the abrupt input of hyper-concentrated flow which was out-of-phase with the discharge of the main stem of the Yellow River was very hard to be simulated accurately (Ta et al., 2014; Yao et al., 2016). In addition, among the ten tributaries, only the Maobula Gully, Xiliu Gully and Hantai Gully have hydrological stations. We estimated the flow and sediment inputs of the other seven tributaries using the measured data from the Maobula Gully, Xiliu Gully, and Hantai Gully based on the method proposed by Dai et al. (2008). This is also a cause leading to large errors, especially during abrupt floods.

\section{Conclusions}

In this study, we used a 1-D numerical model to simulate the flow and sediment transport within the NMRYR. Although the simulated results of sediment concentration and sediment siltation along the Q-B and B-T sub-reaches exhibited large errors, simulations of flow and sediment concentration within the entire reach (i.e., the NMRYR) were satisfactorily acceptable. We hope that the method and key technologies/processes/parameters used in the 1-D numerical simulation model will provide insights into the numerical simulations of flow and sediment transport for the other long rivers characterized by physical and hydrological complexities. 


\section{Acknowledgements}

This study was financially supported by the National Natural Science Foundation of China $(51579113,51309111$, 51309113).

\section{References}

Beasley D B, Huggins L F, Monke E J. 1980. ANSWERS: a model for watershed planning. Transactions of the ASAE, 23(4): 938-944.

Burkow M, Griebel M. 2016. A full three dimensional numerical simulation of the sediment transport and the scouring at a rectangular obstacle. Computers \& Fluids, 125: 1-10.

Chang H H. 1984. Modeling of river channel changes. Journal of Hydraulic Engineering, 110(2): 157-172.

Chen Q H, Fang H W, Wang G Q. 2004. 1-D numerical simulation of unsteady flow and non-uniform sediment transport at the Sanmenxia reservoir in the Yellow River. Advances in Water Science, 15(2): 160-164. (in Chinese)

Chen W B, Liu W C, Wu C Y. 2013. Coupling of one-dimentsional reiver routing model and a three-dimensional ocean model to predict overbank flows in a complex river-ocean system. Applied Mathematical Modelling, 37(9): 6163-6176.

Dai M, Xiong G, Zeng M. 2008. Key technologies of regulation of water and sediment of the reservoirs along the main stream of Yellow River and reservoir operations adjustment of Longyangxia and Liujiaxia reservoirs. Special Report of Yellow River Conservancy Commission. Zhengzhou: Yellow River Conservancy Commission. (in Chinese)

Dou S T, Wang D W, Yu M H, et al. 2014. Numerical modeling of the lateral widening of levee breach by overtopping in a flume with $180^{\circ}$ bend. Natural Hazards and Earth System Sciences, 14(1): 11-20.

Du H Q, Xue X, Wang T. 2014. Estimation of the quantity of aeolian saltation sediments blown into the Yellow River from the Ulanbuh Desert, China. Journal of Arid Land, 6(2): 205-218.

Du H Q, Xue X, Wang T, et al. 2015. Assessment of wind-erosion risk in the watershed of the Ningxia-Inner Mongolia reach of the Yellow River, northern China. Aeolian Research, 17: 193-204.

Fan S S. 1988. Twelve selected computer stream sedimentation models developed in the United States. Washington, DC: Federal Energy Regulatory Commission.

Fang H W, Wang G Q. 2000. 1-D numerical simulation for total sediment transport and its application. Jounal of Basic Science and Engineering, 8(2): 154-164. (in Chinese)

Fryrear D W, Saleh A, Bilbro J D, et al. 1998. Revised wind erosion equation (RWEQ). Technical Bulletin No. 1. USDA-ARS, Lubbock, TX.

Han Q J, Qu J J, Zhang K C, et al. 2009. Wind tunnel investigation of the influence of surface moisture content on the entrainment and erosion of beach sand by wind using sands from tropical humid coastal southern China. Geomorphology, 104(3-4): 230-237.

Hanley N, Faichney R, Munro A, et al. 1998. Economic and environmental modelling for pollution control in an estuary. Journal of Environmental Management, 52(3): 211-225.

Holly Jr F M, Rahuel J L. 1990. New numerical/physical framework for mobile-bed modelling. Part 1: numerical and physical principles. Journal of Hydraulic Research, 28(4): 401-416.

Holly Jr F M, Yang J C, Schovarz P, et al. 1990. CHARIMA: numerical simulation of unsteady water and sediment movements in multiply connected networks of mobile-bed channels. Report No. 343. Iowa City, Iowa: Iowa Institute of Hydraulic Research, University of Iowa.

Hou S Z. 1996. Fluvial process of the Inner Mongolia Reach of the Yellow River in 1987-1993. Yellow River, (9): 43-44. (in Chinese)

Jia X P, Wang H B. 2011. Mineral compositions and sources of the riverbed sediment in the desert channel of Yellow River. Environmental Monitoring and Assessment, 173(3-4): 969-983.

Jia X P, Wang H B, Xiao J H. 2011. Geochemical elements characteristics and sources of the riverbed sediment in the yellow river's desert channel. Environmental Earth Sciences, 64(8): 2159-2173.

Karim M F, Kennedy J F. 1982. IALLUVIAL: a commuter based discharge and sediment routing for alluvial streams and its application to the Missouri River. Report No. 250. Iowa City, Iowa: Iowa Institute of Hydraulic Research, University of Iowa.

Krishnappan B G. 1981. Users manual: unsteady, non-uniform, mobile boundary flow model-MOBED. Burlington, Ontario: Hydraulic Division, National Water Research Institute.

Laflen J M, Lane L J, Foster G R. 1991. WEPP: a new generation of erosion prediction technology. Journal of Soil and Water Conservation, 46(1): 34-38. 
Li Y T, Shang Q M. 1998. Modeling of sediment transport in unsteady flow. Journal of Sediment Research, (1): 81-87. (in Chinese)

Liang G T, Gao Y T, Liang Y P, et al. 1999. Principles and application for mathmatical model for one-dimension unsteady sediment flow. Jounal of Sediment Research, (4): 44-48. (in Chinese)

Luan Z Y, Jin Q. 2016. Research on water-sediment numerical simulation of middle and lower reaches of the Yangtze River and estuary. Procedia Engineering, 154: 582-588.

Martins R. 1989. Recent Advances in Hydraulic Physical Modelling. Netherlands: Kluwer Academic Publisher, 1-2.

Merritt W S, Letcher R A, Jakeman A J. 2003. A review of erosion and sediment transport models. Environmental Modelling \& Software, 18(8-9): 761-799.

Molinas A M, Yang C T. 1986. Computer program user's manual for GSTARS. Denver, Colorado: U.S. Bureau of Reclamation Engineering and Research Center.

Nakato T. 1990. Tests of selected sediment-transport formulas. Journal of Hydraulic Engineering, 116(3): 362-379.

Ong C. Knight D. 1987. Hybrid MacCormack and implicit beam-warming algorithms for a supersonic compression corner. AIAA Journal, 25(3): 401-407.

Onishi Y. 1994. Sediment transport models and their testing. In: Chaudhry M H, Mays L W. Computer Modeling of Free-surface and Pressurized Flows. Netherlands: Springer, 281-312.

Papanicolaou A N, Bdour A, Wicklein E. 2004. One-dimensional hydrodynamic/sediment transport model applicable to steep mountain streams. Journal of Hydraulic Research, 42(4): 357-375.

Papanicolaou A N, Elhakeem M, Krallis G, et al. 2008. Sediment transport modeling review-current and future developments. Journal of Hydrualic Engineering, 134(1): 1-14.

Peng Y, Zhang H W. 2006. 1-D numerical simulation of unsteady flow and sedimentation transport at the Three Gorges Reservoir (TGR). Journal of Hydrodynamics, 21(3): 285-292. (in Chinese)

Przedwojski B, Błażejewski R, Pilarczyk K W. 1995. River Training Techniques: Fundamentals, Design and Applications. Balkema, the Netherlands: CRC Press, 1.

Qin Y. 2009. Mechanics of river course response to river environment change and control strategy-for the Ning-Mong Section of the Yellow River. PhD Dissertation. Xi'an: Xi'an University of Technology. (in Chinese)

Ren R X, Tong G Q, Li J, et al. 2004. Application of one-dimensional non-steady flow model to water regulation of the Yellow River. Yellow River, 26(12): 19-21. (in Chinese)

Rodi W. 2006. DNS and LES of some engineering flows. Fluid Dynamics Research, 38(2-3): 145-173.

Runkel R L, Broshears R E. 1991. OTIS: one-dimensional transport with indischarge and storage (OTIS): a solute transport model for small streams. CADWES Technical Report 91-01. Boulder, Colorado: University of Colorado.

Shao Y P. 2001. A model for mineral dust emission. Journal of Geophysical Research, 106(D17): 20239-20254.

Spasojevic M, Holly Jr F M. 2000. Field data and 3D mobile-bed modeling: help or hindrance. In: Proceedings of the 4th International Conference on Hydroinformatics. Cedar Rapids: International Association of Hydraulic Engineering and Research.

Su T, Wang SJ, Mei Y G, et al. 2015. Comparison of channel geometry changes in Inner Mongolian reach of the Yellow River before and after joint operation of large upstream reservoirs. Journal of Geographical Sciences, 25(8): 930-942.

Ta W Q, Yang G S, Qu J J, et al. 2003. The effect of the coarse aeolian sand on siltation of the Inner Mongolian Reach of the Yellow River. Environmental Geology, 43(5): 493-502.

Ta W Q, Jia X P, Wang H B. 2013. Channel deposition induced by bank erosion in response to decreased flows in the sand-banked reach of the upstream Yellow River. CATENA, 105: 62-68.

Ta W Q, Wang H B, Jia X P. 2014. Aeolian process-induced hyper-concentrated flow in a desert watershed. Journal of Hydrology, 511: 220-228.

Termini D. 2011. 1-D numerical simulation of sediment transport in alluvial channel beds. European Journal of Environmental and Civil Engineering, 15(2): 269-292.

Thomann R V. 1982. Verification of water quality models. Journal of the Environmental Engineering Division, 108(5): 923940.

Viney N R, Sivapalan M, Deeley D. 2000. A conceptual model of nutrient mobilisation and transport applicable at large catchment scales. Journal of Hydrology, 240(1-2): 23-44.

Wang S Q. 1996. Mathematical model for predicting the fluvial processes in the Yellow River. Advances in Water Science, 7(3): 193-199. (in Chinese)

Wu W M, Vierira D A, Wang S Y. 2004. One-dimensional numerical model for nonuniform sediment transport under unsteady flows in channel networks. Jounral of Hydraulic Engineering, 130(9): 914-923. 
Wu W M, Marsooli R, He Z G. 2012. Depth-averaged two-dimensional model of unsteady flow and sediment transport due to noncohesive embankment break/breaching. Jounral of Hydraulic Engineering, 138(6): 503-516.

Xu J X. 2013. Erosion and sediment yield of 10 small tributaries joining Inner Mengolia reach of upper Yellow River in relation with coupled wind-water processes and hyperconcentrated flows. Journal of Sediment Research, (6): 28-37. (in Chinese)

Yang G S, Liu Y Y, Shi P J. 1987. Estimation of the aeolian sand entering the Yellow River. Chinese Science Bulletin, 13(13): 1017-1021. (in Chinese)

Yao H F, Shi C X, Shao W W, et al. 2016. Changes and influencing factors of the sediment load in the Xiliugou Basin of the upper Yellow River, China. CATENA, 142: 1-10.

Yao Z Y, Ta W Q, Jia X P, et al. 2011. Bank erosion and accretion along the Ningxia-Inner Mongolia reaches of the Yellow River from 1958 to 2008. Geomorphology, 127(1-2): 99-106.

Yen B C. 1993. Criteria for evaluation of watershed models. Journal of Irrigation and Drainage Engineering, 119(3): 429-442.

Yu M H, Shen K, Wu S B, et al. 2013. An experimental study of interaction between bank collapse and river bed evolution. Advances in Water Science, 24(5): 675-682. (in Chinese)

Zhang H W, Zhao L J, Wang G Q, et al. 2003. Quasi-2D mathematical model for morphology of the Lower Yellow River. Journal of Hydrolic Engineering, (4): 1-7.

Zhao W, Chen X, Hou, S. 1999. Variations of the alluvial process of the Yellow River in Ningxia Province and Inner Mongolia Province. Yellow River, 21(6): 11-14. (in Chinese)

Zhou L Y, Cui Z H, Luo Q S. 2012. Water and sediment variation and characteristics of scouring and deposition of Ningxia-Inner Mongolia Reach of the Yellow River. Yellow River, 34(1): 25-26. (in Chinese) 